\title{
Research Paper: The Role of Speech-language Pathologists in the Hospitals of Pakistan
}

\author{
Mehwish Zikria $^{1}$ (D), Nazia Mumtaz ${ }^{2}$ (D), Ghulam Saqulain ${ }^{3 *}$ (i), Muhammad Naveed Babur ${ }^{4}$ (D)
}

1. Department of Pediatrics, District Head Quarter Hospital, Mianwali, Punjab, Pakistan.

2. Department of Speech Language Pathology, Faculty of Rehabilitation \& Allied Health Sciences, Riphah International University, Islamabad, Pakistan.

3. Department of Otorhinolaryngology, Capital Hospital PGMI, Islamabad, Pakistan.

4. Department of Rehabilitation Sciences, Faculty of Allied Medical Sciences, Isra University, Islamabad, Pakistan.

\begin{tabular}{|l|l|}
$\begin{array}{c}\text { Use yur device to scan } \\
\text { and read the article online }\end{array}$ & $\begin{array}{l}\text { Citation: Zikria M, Mumtaz N, Saqulain G, Naveed Babur M. The Role of Speech-language Pathologists in the Hospitals of } \\
\text { Pakistan. Iranian Rehabilitation. Journal. 2021; 19(2):165-172. http://dx.doi.org/10.32598/irj.19.2.1335.1 }\end{array}$ \\
dolinttp://dx.doi.org/10.32598/irj.19.2.1335.1
\end{tabular}

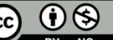

Article info:

Received: 26 Jan 2021

Accepted: 15 Jun 2021

Available Online: 01 June 2021

\section{Keywords:}

Healthcare, Interdisciplinary approach, Knowledge, Perception, Speech-lnguage pathologist

\section{ABSTRACT}

Objectives: This study aimed to assess the knowledge and perception of the role of speech therapists by other medical professionals in public hospitals.

Methods: This cross-sectional study recruited 200 healthcare professionals with >1year of job experience at the workplace of both genders and any age. Besides, the study subjects were selected using a non-probability convenience sampling approach. The study sample was recruited from 25 District and Tehsil Headquarter Hospitals from April 1, 2019, to September 30, 2019. A basic demographic datasheet and the Knowledge, Attitude, and Practices (KAP) survey were used for data collection. Statistical analysis was performed in SPSS.

Results: Out of the total 200 eligible professionals from different departments, the Mean \pm SD scores of the responses were highest $(75.14 \pm 24.87)$ in pediatric medical professionals. Moreover, the lowest scores (46.70 \pm 0.01$)$ concerned Intensive Care Unit (ICU) experts; this difference was statistically significant $(\mathrm{P}<0.001)$. Similarly, a significantly higher Mean \pm SD score of $74.05 \pm 20.04$ was noted for those working day shifts, compared to that of $(35.01 \pm 8.52)$ those working in night shifts $(\mathrm{P}<0.001)$.

Discussion: The knowledge and perception of different healthcare professionals serving in public hospitals vary regarding the role of SLPs. Such differences concern their profession, with pediatrics presenting the highest level of understanding, followed by general medicine. However, psychiatry and ENT professional provided the least understanding in this area. The professionals working in day shifts suggested better knowledge and perception, compared to night shifts staff. 


\section{Highlights}

- KAP's of HCP's considerably differ regarding the role of SLP's.

- HCP's were highest in pediatrics, while those in the psychiatry and ENT presented the lowest KAP's regarding SLP's.

- The KAP's of HCP's working in night shifts was lower than that of those in day shifts.

\section{Plain Language Summary}

Cooperation and referral between different specialties are necessary to better address patient needs. Speech therapists assess and provide treatment for speech, language, and feeding difficulties. However, achieving this goal is only possible when different professionals are aware of the role of speech therapists; so that can guide and refer these patients to them. The lack of knowledge on the role of speech therapy results in the delayed treatment of these cases; thus, the current study aimed to determine the knowledge and perception of the role of speech therapists in other medical professionals working in public hospitals, using a survey questionnaire. In total, 200 professionals completed the Knowledge, Attitude, and Practices survey; of whom, we noted that those working in children and general medicine departments had the best, while those in psychiatry and ENT wards had the least understanding of the role of speech therapy. These findings can help plan future educational activities for specialties where deficiency is found, thus improving patient care.

\section{Introduction}

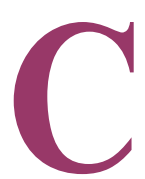

onsidering the welfare of patients, over the last few decades, it has been realized that a single professional cannot ideally meet individual patient's requirements; thus, interdisciplinary collaboration is essential [1]. This approach has its challenges, demanding the time as well as efforts of different professionals; the benefits of the patients and professionals cannot also be undermined. Complications arise when professionals are not well aware of the roles of the other profession; however, the same can be facilitated by reciprocal learning of other specialties [2]. Accordingly, highlighting the significance of the training of interdisciplinary approach is of great significance [3]. It is recognized that the nature and frequency of referrals are definitely affected; this condition is due to the lack of knowledge of other specialties and their role in patient management. Thus, it helps to increase the complication rate as well as the cost of healthcare and the duration of hospital stay, while compromising patients' Quality of Life (QoL) [3, 4].

Speech-Language Pathologists (SLPs) are skilled professionals involved in the evaluation and management of patients with speech, language, or swallowing difficulties. Moreover, they work as part of an interdisciplinary team along with other professionals. Such other professionals include medical specialists, otolaryngologists, psychologists, psychiatrists, pediatricians, physiotherapists, audiologists, nurses, social workers, and occupational therapists [5]. A multitude of difficulties may arise when the members of the interdisciplinary team are unacquainted with the roles of other members [6].

Interdisciplinary cooperation warrants that, to understand patients' needs and for appropriate decisionmaking and referrals to the SLPs, various healthcare professionals require adequate knowledge regarding the impact of SLPs in patients' rehabilitation [7].

Rehabilitating swallowing and communication in affected cases is the main role of SLP while enhancing the patient's QoL [5]. The scope of practice differs according to institutional settings; however, in acute care settings, SLPs prevent, evaluate, and treat multiple disorders, including oral-motor; speech; language; linguistic; cognitive; as well as swallowing disorders and medical problems, which may be progressive $[5,8]$. Rapid changes are occurring in practice due to new evidence and clinical guidelines, like the International Classification of Functioning (ICF) model by the World Health Organization (WHO). Furthermore, diagnosis and treatment approaches are developing; thus, the SLP profession entails professional consideration and modifications [9]. They should also know about augmentative and alternative communication for better patient management [10]. The interdisciplinary team needs to keep abreast of the role of SLPs; there exists an increasing 
need to analyze the level of knowledge about the role of SLPs among other health professionals. This is because modern healthcare systems have complexities, as well as different assessment and treatment strategies. These include the domain of different professionals; thus, professionals are required to work in a team to enhance collaboration between different professionals for the benefit of patient care [11]. In Pakistan, interdisciplinary collaboration remains lacking. Additionally, professionals attempt to treat patients in isolation. SLP is a comparatively new specialty in Pakistan; therefore, assessing the KAP of Healthcare Professionals (HCP) regarding SLP is essential. The relevant data could help to improve the recognition of their role and better patient care.

Thus, the present study aimed to assess knowledge and perception regarding speech-language pathologists/therapists by others healthcare professionals in public hospital settings. This study could provide an insight respecting the current knowledge and perception about the role of SLPs among various medical professionals. The results can also highlight the need for corrective measures and help in better evidence-based patient management; SLPs are the integral members of the rehabilitation team. Accordingly, their role needs optimum consideration in interdisciplinary teams.

\section{Methods}

This cross-sectional survey was conducted in the following departments: general medicine, pediatrics, psychiatry, general surgery, Otorhinolaryngology (ENT), including audiology, Intensive Care Unit (ICU), and physiotherapy of 25 District Headquarter (DHQ) and\& Tehsil Headquarter Hospitals of Punjab City, Pakistan from April 1, 2019, to September 30, 2019. In total, 200 medical and allied professionals, with $>1$-year service experience were recruited using the non-probability convenience sampling method. The study sample included both genders of any age, working in day and night shifts. Professionals who were working in tertiary care hospitals and private hospitals, those working as house officers, and internees, and those who did not consent for inclusion were excluded from the study. A sample size of 227 was calculated using the following sample size formula:

$$
N=\frac{Z_{a / 2}^{2}{ }^{*} p^{*}(1-p) * D E F F}{d^{2}}
$$

and taking a prevalence proportion of 0.82 [12]; DEFF of 1 ; using $5 \%$ absolute precision, and $95 \%$ Confidence Interval (CI). a basic demographic datasheet and the Knowledge, Attitude, and Practices (KAP) survey de- veloped by King EE [11] were used for data collection. The questionnaire comprises 3 sections; the first respects the demographic and professional details of the respondents. The second section concerns the assessment of the perception of professionals about the importance of SLP; its scores range from 1 to 4 , extending from 1 for least important to 4 for most important. The third section evaluates knowledge regarding the scope of SLP, with response options of yes, no, and uncertain. The present study was conducted following the clearance of the Advanced Studies and Research Committee of Isra University Islamabad regarding ethical issues vide registration number 1609-M.Phil SLP-004 dated November 29, 2018. An informed consent form was obtained from the study participants and their confidentiality was observed. All the target departments were visited during the day and night shifts. The research participants who met the inclusion criteria were included in the current study.

The obtained data were analyzed in SPSS. Descriptive statistics were used, including Mean \pm SD for quantitative variables; frequency and percentage were calculated for qualitative variables. Independent Sample t-test with 95\%CI and one-way Analysis of Variance (ANOVA) were employed to determine correlations between gender, profession, department, shift, and experience. $\mathrm{P}<0.05$ was considered significant.

\section{Results}

The Mean \pm SD age of the study sample was $36.64 \pm 11.17$ years. They reported a Mean $\pm \mathrm{SD}$ work experience of $6.00 \pm 4.27$ years (Figure 1) and a majority of them $(62 \%)$ had $<6$ years of work experience. The study sample comprised 131 (65.5\%) males and 69 (34.5\%) females. Profession-wise majority of 53 (26.5\%) of the study subjects were physicians belonging mainly to the medical department 62 (31\%) with most 105 (52.5\%) practicing day shift duty and only 28 (14\%) were involved in the ICU (Table 1).

Of the section III questions of the questionnaire, mean correct responses presented were recorded; the relevant correlations were noted using Independent Samples ttest and ANOVA (Table 1). There Mean \pm SD score of correct responses by females (58.92 \pm 26.94$)$ was higher, compared to males $(53.71 \pm 23.86)$; however, the difference was not significant $(\mathrm{P}=0.162)$. Furthermore, the higher Mean $\pm \mathrm{SD}$ correct responses belonged to psychologists $(62.74 \pm 25.09)$ and the lowest concerned dieticians (42.51 \pm 20.46$)$; however, the difference in the mean scores was not significant for various professions $(\mathrm{P}=0.517)$. Regarding various departments, the 
Table 1. Demographic and professional data of the study subjects $(\mathrm{N}=200)$

\begin{tabular}{|c|c|c|c|c|}
\hline \multirow{2}{*}{ Variables } & \multirow{2}{*}{ Categories } & \multirow{2}{*}{ Frequency/No. (\%) } & \multicolumn{2}{|l|}{ t-test/ANOVA Statistics } \\
\hline & & & Mean $\pm S D$ (For Mean Correct Responses) & $t / F, P$ \\
\hline \multirow{2}{*}{ Gender } & Male & $131(65.5)$ & $53.71 \pm 23.86$ & \multirow{2}{*}{$\begin{array}{c}-1.402 \\
0.162\end{array}$} \\
\hline & Female & $69(34.5)$ & $58.92 \pm 26.94$ & \\
\hline \multirow{7}{*}{ Profession } & Doctor & $53(26.5)$ & $56.49 \pm 25.35$ & \multirow{7}{*}{$\begin{array}{l}0.871 \\
0.517\end{array}$} \\
\hline & Nurse & $44(22)$ & $53.65 \pm 23.81$ & \\
\hline & Psychologist & $22(11)$ & $62.74 \pm 25.09$ & \\
\hline & Dietitian & $8(4)$ & $42.51 \pm 20.46$ & \\
\hline & Audiologist & $9(4.5)$ & $50.36 \pm 19.76$ & \\
\hline & Physiotherapists & $25(12.5)$ & $58.68 \pm 22.36$ & \\
\hline & Psychiatrist & $39(10.5)$ & $54.00 \pm 29.11$ & \\
\hline \multirow{7}{*}{ Department } & Medicine & $62(31)$ & $53.78 \pm 28.47$ & \multirow{7}{*}{$\begin{array}{c}4.241 \\
0.0001\end{array}$} \\
\hline & Surgery & $23(11.5)$ & $58.78 \pm 11.01$ & \\
\hline & Pediatrics & $26(13)$ & $75.14 \pm 24.87$ & \\
\hline & ENT & $16(8)$ & $47.51 \pm 27.54$ & \\
\hline & ICU & $28(14)$ & $46.70 \pm 0.00$ & \\
\hline & Physiotherapy & $20(10)$ & $57.34 \pm 24.62$ & \\
\hline & Psychiatry & $25(12.5)$ & $49.87 \pm 28.57$ & \\
\hline \multirow{2}{*}{ Shift } & Day & $105(52.5)$ & $74.05 \pm 20.04$ & \multirow{2}{*}{$\begin{array}{c}16 . .6 \\
0.0001\end{array}$} \\
\hline & Night & $95(47.5)$ & $35.01 \pm 8.52$ & \\
\hline \multirow{2}{*}{ Experience_ } & $<6$ & $124(62)$ & $60.79 \pm 24.39$ & \multirow{2}{*}{$\begin{array}{l}2.366 \\
0.019\end{array}$} \\
\hline & $\geq 6$ & $76(38)$ & $52.27 \pm 24.94$ & \\
\hline
\end{tabular}

Пranian Rehabilitation Journal

Mean \pm SD score of correct responses was highest among those in the pediatric department $(75.14 \pm 24.87)$ and lowest among those working in the ICU (46.70 \pm 0.00$)$; the difference was statistically significant $(\mathrm{P}<0.001)$.

The was a shift-wise significant difference between day shift staff with the highest scores $(74.05 \pm 20.04)$, compared to the night shift staff $(35.01 \pm 8.52)(\mathrm{P}<0.001)$. The was an experience-wise significant difference between the study subjects, with those having less than 6 years of experience obtaining higher scores $(60.79 \pm 24.39)$, compared to the seniors with an experience of 6 years and more $(52.27 \pm 24.94)(\mathrm{P}=0.019)$.
The research participants' response to monthly communication/referral to SLP/SLT, revealed that 55 (27.5\%) of the subjects had no communication; however, a majority $60(30 \%)$ communicated 1-10 times/month and 61 $(30.5 \%)$ referred no cases. The majority 89 (44.5\%) of the study samples were unfamiliar with SLP'S role. Moreover, $155(77.5 \%)$ of the explored healthcare professionals did not receive and did not know anyone to receive these SLP services (Table 2).

As per Table 3, respecting stroke/ brain injury patient SLP management, 38 (19\%) of the examined healthcare professionals believed that there is no role and for ventilator support, 94 (47\%) of HCPs ranked it as important, and only $8(4 \%)$ addressed it is as extremely important. 
Table 2. The perception of the value of speech-language pathologists in the study sample $(\mathrm{N}=200)$

\begin{tabular}{|c|c|c|c|c|c|}
\hline \multirow{2}{*}{ Questions } & \multicolumn{5}{|c|}{ Response Frequency/No. (\%) } \\
\hline & 0 Times/Month & $\begin{array}{l}\text { 1-10 Times/ } \\
\text { Month }\end{array}$ & $\begin{array}{l}\text { 10-20 Times/ } \\
\text { Month }\end{array}$ & $\begin{array}{c}>\mathbf{2 0} \\
\text { Times/Month }\end{array}$ & Do Not Know \\
\hline $\begin{array}{l}\text { 5. How often do you contact or } \\
\text { refer to Speech Therapists? }\end{array}$ & $55(27.5)$ & $60(30)$ & $30(15)$ & $27(13.5)$ & $28(14)$ \\
\hline $\begin{array}{l}\text { 6. What is the number of cases } \\
\text { cared for jointly by you and the } \\
\text { speech therapist? }\end{array}$ & $61(30.5)$ & $62(31)$ & $25(12.5)$ & $27(13.5)$ & $25(12.5)$ \\
\hline $\begin{array}{l}\text { 7. What is your level of knowl- } \\
\text { edge of the role of the speech } \\
\text { therapist in the hospital? }\end{array}$ & $89(44.5)$ & $64(32)$ & $20(10)$ & $27(13.5)$ & 0 \\
\hline $\begin{array}{l}\text { 8. Did you or someone you } \\
\text { know received speech services? }\end{array}$ & \multicolumn{2}{|c|}{ Yes } & \multicolumn{3}{|c|}{ No } \\
\hline
\end{tabular}

Iranian Rehabilitation Journal

Regarding the cases in a vegetative state on tube feeding SLP's role was recognized as not important by 38 (19\%), and extremely important by 56 (28\%). For dysphagia, SLP's role was considered not important by $36(18 \%)$ and extremely important by $24(12 \%)$ of the investigated healthcare professionals. SLP's role in the management of vomiting and acute bowel obstruction was recognized as not at all important by 36 (18\%) study subjects. For managing cases with head and neck radiation, SLP's role was recognized by $94(47.5 \%)$ of the explored healthcare professionals as not at all important. For fluency difficulties, $100(50 \%)$ of the study participants recognized SLP's role is extremely important. For managing hearing difficulties, SLP's role was considered not at all important by 124 (62\%) study participants. For managing voice problems, only 58 (29\%) of the study subjects considered SLP's role is extremely important. Concerning patients with communicative abilities that can improve by speech therapy, 85 (42.5\%) of the study sample considered no role for it. Moreover, 73 (36.5\%) of the study subjects stated swallowing cannot improve with speech therapy. Overall, only $45(22.5 \%)$ of the examined professionals believed that the services of speech professionals could significantly contribute to the care of patients in hospital settings (Table 3 ).

\section{Discussion}

Inter-professional collaboration is a current need. Besides, it is increasing with realizing that not a single profession alone can cater to the complex requirements of a patient. Instead of working in isolation, the recommended interdisciplinary approach involves a set of professionals with diverse areas of expertise working together to provide maximum benefit to the patients [13].

In the present study, a very low perception of the role of SLP was noted with poor perception, communication, and referral to SLPs as well as unfamiliarity with

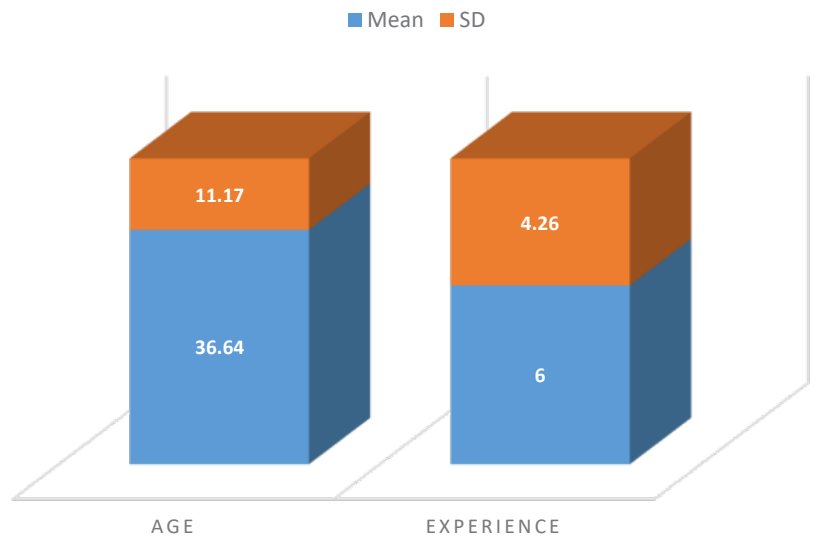

Figure 1. Age and experience distribution in the study sample $(\mathrm{N}=200)$ 
Table 3. Participants understanding of the role of SLP $(\mathrm{N}=200)$

\begin{tabular}{|c|c|c|c|c|c|}
\hline \multirow{2}{*}{\multicolumn{2}{|c|}{ Queries }} & \multicolumn{4}{|c|}{ Is it Important? (\%) } \\
\hline & & Not At All N (\%) & Possibly N (\%) & Important $\mathbf{N}$ & Extremely N (\%) \\
\hline \multirow{9}{*}{ 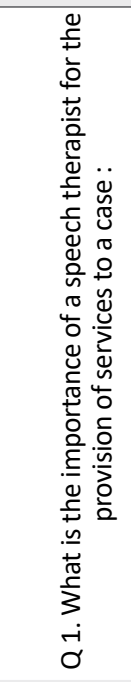 } & With stroke or brain injury & $38(19)$ & $126(63)$ & $25(12.5)$ & $11(5.5)$ \\
\hline & Is on ventilator for several days & $33(16.5 \%)$ & 65 (32.5\%) & $94(47 \%)$ & $8(4 \%)$ \\
\hline & $\begin{array}{l}\text { Is in a persistent vegetative } \\
\text { state with tube feeding }\end{array}$ & $38(19)$ & $65(32.5)$ & $41(20.5)$ & $56(28)$ \\
\hline & $\begin{array}{l}\text { Is having trouble swallowing } \\
\text { food }\end{array}$ & $36(18)$ & $67(33.5)$ & $73(36.5)$ & $24(12)$ \\
\hline & $\begin{array}{l}\text { With acute vomiting due to } \\
\text { bowel obstruction }\end{array}$ & $36(18)$ & $63(31.5)$ & $67(33.5)$ & $34(17)$ \\
\hline & Is receiving head/neck radiation & 95 (47.5) & $73(36.5)$ & $32(16)$ & 0 \\
\hline & Has fluency difficulty & $31(15.5)$ & $28(14)$ & $41(20.5)$ & $100(50)$ \\
\hline & Has hearing difficulty & $124(62)$ & $9(4.5)$ & $34(17)$ & $33(16.5)$ \\
\hline & Has voice difficulty & $29(14.5)$ & $71(35.5)$ & $42(21)$ & $58(29)$ \\
\hline & & Yes & \multicolumn{2}{|c|}{ No } & Uncertain \\
\hline \multicolumn{2}{|c|}{$\begin{array}{l}\text { Q 2. Speech therapy can change a patient's abili- } \\
\text { ties to communicate. }\end{array}$} & $53(26.5)$ & \multicolumn{2}{|c|}{$85(42.5)$} & $62(31)$ \\
\hline \multicolumn{2}{|c|}{$\begin{array}{l}\text { Q 3. Speech therapy can change a patient's abil- } \\
\text { ity to swallow. }\end{array}$} & $52(26)$ & \multicolumn{2}{|c|}{$73(36.5)$} & $75(37.5)$ \\
\hline \multicolumn{2}{|c|}{$\begin{array}{l}\text { Q 4. In a hospital setting, speech therapists can } \\
\text { contribute substantially to patient care. }\end{array}$} & $45(22.5)$ & \multicolumn{2}{|c|}{$99(49.5)$} & $56(28)$ \\
\hline
\end{tabular}

Iranian Rehabilitation Journa

their role. Similarly, in a Malaysian study by Xinyi et al., the lack of awareness as well as training was revealed, with $58 \%$ of them rarely or never referring cases with dysphagia to SLP [14]. Moreover, Kamal et al. reported that compared to professionals belonging to Queensland, the healthcare professionals of Malaysia lacked awareness respecting dysphagia as well as the role of SLPs in its management. They also highlighted barriers that required addressing to rectify this deficiency [15]. In contrast, King EE signified a positive perception regarding the significance of SLP [11]. This difference could be because SLP in Pakistan is a new young field and the medical and allied curricula are deficient; therefore, there is a lack of perception and the role of SLPs among different professionals.

In the present study, regarding understanding the role of SLP's in managing stroke/brain injury, a majority of examined healthcare professionals did not consider the role of SLPs as important; except in cases with fluency difficulty, where the majority agreed on the important role of SLPs. In contrast to our study, Byrne and Pettigrew [16] investigated occupational physical therapy professionals in a unit managing stroke patients. Accordingly, they reported that the study participants had an adequate overall understanding of the role of speech professionals; however, they failed to conceptualize numerous essential treatment approaches provided by SLPs. Additionally, the present study data revealed that SLPs were deficient in knowledge. This is because when asked about whether speech therapy can bring improvement in communicative abilities, swallowing abilities, and patient care within hospital settings, only a minority agreed that SLPs could make any change. In contrast, Intezar et al. reported that audiologists had significant knowledge and awareness of SLP's beneficial role for HI patients [17]. This could be because SLP practice is quite related to audiology practice. Furthermore, the training programs for audiology and speech, i.e., conducted in the country share some modules; thus, providing better knowledge and perception to audiologists regarding SLP. There was an impact of speech therapy services; however, there was a dire need for training to assist allied professionals in understanding the speech-language pathology profession [11]. 
As regards understand the scope of practice of SLP, a higher mean score of correct responses was noted for females, compared to males in the present study. Moreover, there was a higher mean score among psychologists, followed by physiotherapists and physicians; the lowest rates were observed among dieticians, with no significant difference $(\mathrm{P}=0.517)$. In contrast, King reported statistically significant differences between the scores of different groups of professionals concerning maximum scores for physicians [11]. Thus, inter-professional cooperation and education are required for the promotion of SLP's role for feeding, as well as communicational disorders [18], with special reference to physicians in Pakistan. In our study, the mean score of correct responses was highest in those in the pediatric department, followed by the surgery department, physiotherapy, medicine, and ICU in decreasing order with statistically significant differences $(\mathrm{P}<0.001)$. However, in another study, the difference in results between various departments was not significant $(\mathrm{P}=0.095)$ [11]. Sullivan and Cleave examined the students of different healthcare $\leq$ programs, including physio- and occupational therapy, nursing, as well as medicine. Subsequently, they revealed that those in occupational therapy and physiotherapy were more knowledgeable regarding the role of SLPs, compared to medicine and nursing students [7]. Moreover, those practicing day shift duties presented the highest scores, compared to night shift; this difference was statistically significant $(\mathrm{P} \leq 0.001)$. Thus, the shift of the explored staff was not probably being rotated in different shifts. In contrast, King EE reported no significant difference among different shifts $(\mathrm{P}=0.27)$ [11]. Those having $<6$ years of experience indicated higher scores, compared to seniors with an experience of $\geq 6$ years $(\mathrm{P}=0.019)$. These data indicated that juniors were more inclined to learn about other specialties' roles and teamwork. A study involving dentists reported that a majority of dentists had an impression that SLPs play a vital role in the health professional team; however, their responses were poor towards questions related to the normal development of speech and language (26\%) as well as speech-language disorders (18\%). Furthermore, there was no significant association with age, gender, and experience in this area [19].

There is a strong need for improving education in connection with the role of SLPs in acute care settings [11]. The scope of practice of SLP is correlated with the WHO's ICF, the statistical Manual of Mental Disorders, and the American Psychiatric Association's Diagnostic criteria [20]. It is to emphasize here that clinicians need to stay current with advances in SLP practice. This is achievable using research literature and regularly participating in continuing medical education to supplement advances in the profession and information in the scope of practice [21]. SLPs with the main objective of optimization of patient's abilities to swallow and communicate can improves patients' QoL.

This study was limited to Punjab Province and overlooked the provinces, i.e., comparatively behind Punjab respecting healthcare facilities, like Baluchistan. Thus, the obtained results cannot be generalized to other populations. Moreover, using the probability sampling method and more rigorously controlling the sample for age and qualification might have biased the collected results.

\section{Conclusion}

The knowledge and perception of different healthcare professionals serving in public hospitals regarding the role of SLPs varied according to their profession; pediatrics professionals presented the highest level of understanding, followed by general medicine. However, professionals in psychiatry and ENT departments expressed the least understanding regarding the role of SLPs. The professionals working on the day shift indicated better knowledge and perception, compared to night shift workers.

\section{Ethical Considerations}

\section{Compliance with ethical guidelines}

All ethical principles are considered in this article. The participants were informed of the purpose of the research and its implementation stages. They were also assured about the confidentiality of their information and were free to leave the study whenever they wished, and if desired, the research results would be available to them. A written consent has been obtained from the subjects. principles of the Helsinki Convention was also observed.

\section{Funding}

This research did not receive any grant from funding agencies in the public, commercial, or non-profit sectors.

\section{Authors' contributions}

Conceptualization and Supervision: Nazia Mumtaz, Ghulam Saqulain \& Muhammad Naveed Babur; Methodology, Resources, and Data Curation: Mehwish Zikria, Nazia Mumtaz; Formal Analysis and Writing original draft Preparation: Ghulam Saqulain, Mehwish 
Zikria; Writing - review and editing, and Supervision: Nazia Mumtaz, Muhammad Naveed Babur.

\section{Conflict of interest}

The authors declared no conflicts of interest

\section{References}

[1] Green BN, Johnson CD. Inter professional collaboration in research, education, and clinical practice: Working together for a better future. The Journal of Chiropractic Education 2015; 29(1):1-10. [DOI:10.7899/JCE-14-36] [PMID] [PMCID]

[2] Björklund K, Silén C. Occupational therapy and physiotherapy students' communicative and collaborative learning in an interprofessional virtual setting. Scandinavian Journal of Occupational Therapy. 2021; 28(4):264-73. [DOI:10.1080/110381 28.2020.1761448] [PMID]

[3] Loy B, Micheff H, Nguyen K, O’Brien V. Interprofessional Collaboration between occupational therapists and nurses in an acute care setting: An exploratory study[MSc. thesis]. California: Dominican University of California; 2015. [DOI:10.108 0/11038128.2020.1761448]

[4] Smith E, Mackenzie L. How occupational therapists are perceived within inpatient mental health settings: The perceptions of seven Australian nurses. Australian Occupational Therapy Journal. 2011; 58(4):251-60. [DOI:10.1111/j.14401630.2011.00944.x] [PMID]

[5] American Speech-Language-Hearing Association. Scope of Practice in Speech-Language Pathology. Maryland: American Speech-language Association; 2007. https:/ / www.govst. edu/uploadedFiles/Academics/Colleges_and_Programs/ pdf

[6] Norwich B. Ideological dilemmas in special needs education: Practitioners' views. Oxford Review of Education. 1993; 19(4):527-46. [DOI:10.1080/0305498930190408]

[7] Sullivan A, Cleave PL. Knowledge of the roles of speech-language pathologists by students in other health care programs. Journal Of Speech Language Pathology and Audiology. 2003; 27(2):98-107. https://cjslpa.ca/files/2003 JSLPA_Vol 27/ No_02_93-140/Sullivan_Cleave_JSLPA_2003.pdf

[8] Hallowell B. Aphasia and other acquired neurogenic language disorders: A guide for clinical excellence. California: Plural Publishing; 2017. https://www.google.com/books/ edition/Aphasia_and_Other_Acquired_Neurogenic_La/rLnDAAAQBAJ?hl=en\&gbpv=1\&printsec=frontcover

[9] Johnson AF, Jacobson BH. Medical speech-language pathology: A practitioner's guide. New York: Thieme Medical Publishers; 2011. https://www.google.com/books/ edition/Medical_Speech_Language_Pathology/kDj7 VYGAhUC?hl=en\&gbpv $=0$

[10] Khan SG, Butt AK, Noreen H, Butt AK, Iftikhar N, Khan M, et al. Perception of speech and language pathologists towards augmentative and alternative communication in Pakistan. Journal of the Pakistan Medical Association. 2019; 69(2):164-7. [PMID]
[11] King EE. Knowledge and perception of speech-language pathologists by allied health personnel in the acute care hospital setting. Merge. 2017; 1:1-34. https://athenacommons. muw.edu/merge/vol1/iss1/1/

[12] Zaidi S, Idrees N, Riaz A. Primary health care systems (PRIMASYS): Comprehensive case study from Pakistan. Geneva: World Health Organization; 2017. https:/ /www.who. int/alliance-hpsr/projects/AHPSR-PRIMASYS-Pakistancomprehensive-v2.pdf

[13] O'Daniel M, Rosenstein AH. Professional communication and team collaboration. In: Hughes RG, editor. Patient safety and quality: An evidence-based handbook for nurses. Rockville (MD): Agency for Healthcare Research and Quality; 2008. [PMID]

[14] Xinyi DY, Ahmad A, Vesualingam M. Medical Officers' Awareness, Involvement and Training in Dysphagia Management. Jurnal Sains Kesihatan Malaysia. 2018; 16(1):7-16. [DOI:10.17576/jskm-2018-1601-02]

[15] Kamal RM, Ward E, Cornwell P. Levels of awareness, involvement and training in dysphagia management among other health professionals in Malaysia. Medicine. 2013; 3(1):124. [DOI:10.17576/jskm-2018-1601-02]

[16] Byrne A, Pettigrew CM. Knowledge and attitudes of allied health professional students regarding the stroke rehabilitation team and the role of the Speech and Language Therapist. International Journal of Language \& Communication Disorders. 2010; 45(4):510-21. [DOI:10.3109/13682820903222791] [PMID]

[17] Intezar F, Khan SG, Noreen H, Iftikhar N. Awareness and knowledge of audiologists regarding benefits of speech language therapy for hearing impaired individuals. Journal Riphah College of Rehabilitation Sciences. 2019; 7(2):47-53. [DOI:10.5455/JRCRS.2019070203]

[18] Klein K, Wagner E, Moore K, Amin T, Louw B. Perceptions of medical students of the role of the speech-language pathologist in HIV/AIDS intervention. Poster Presented at: Annual Convention, American Speech-Language-Hearing Association. 12 November 2015; Colorado, USA. http:/ / submissions mirasmart.com/ASHA2015/Itinerary/

[19] Mahmoud HN, , Mahmoud AN. Knowledge and attitudes of Jordanian Dentists toward Speech Language Pathology. Journal of Language Teaching and Research. 2019; 10(6):1298306. [DOI:10.17507/jltr.1006.19]

[20] American Psychiatric Association. Diagnostic and statistical manual of mental disorders. Washington, D.C American Psychiatric Publishing; 2013. [DOI:10.1176/appi. books.9780890425596]

[21] Duchan JF. Impairment and social views of speechlanguage pathology: Clinical practices re-examined. Advances in Speech Language Pathology. 2001; 3(1):37-45 [DOI:10.3109/14417040109003707] 